doubt that the attack of pleuro-pneumonia of both lungs was set up by the blow on the head, as severe cerebral symptoms set in immediately after it was inflicted. It would appear as if the blow had dislodged some septic thrombus from the middle ear and produced thrombosis of some vein or veins entering the lateral sinus, from which septic emboli were carried to the lungs. The source of the sepsis I believe to have been sewer gas, as the house was proved to be very insanitary. Within nine months there occurred in the house one case of pelvic cellulitis, one of diphtheritic sore-throat, two other sore-throats, two cases of acute otitis media, and two of acute rheumatism. All these, I believe, may be caused by sewer gas. The symptoms of acute rheumatism and septicæmia bear such a close resemblance to one another that I need not do more than refer to them. An interesting feature of the case was the absence of rigors, which are usually considered to be diagmostic of septic thrombosis of the lateral sinus. The question arises, Would it have been better to have ligatured the internal jugular vein? I think it would, even in the absence of proof of thrombosis, for it would probably have cut short the illness and diminished the risk to life arising from the extensive inflammation of the lungs.

CASE 2. Subdural abscess and septic thrombosis of the lateral sinus; drainage of abscess and sinus; ligature of internal jugular evein; reconery. - A boy aged fifteen had suffered intermittently for two years from left otorrhoa, which had been treated with antiseptic lotions and powders. A oranulation polypus had been removed from a perforation in the upper part of the membrana tympani during the previous summer. On March 20th, 1894, he was supposed to have caught cold, and on the 23rd he began to suffer from earache and headache. On the 29 th his temperature was $102^{\circ} \mathrm{F}$. There was no loss of appetite, and no sickness or shivering. I first saw him on April Ist and found him in bed, flushed and drowsy; heobjected to light and was very deaf. His temperature was $103.6^{\circ}$, the pulse 90 , and the respiration 24 . The left side of his face was puffy. The discharge from the ear was most offensive. There was slight tenderness over the mastoid antrum and cells, and marked tenderness over the large vessels in the neck. There were no physical signs of any lung or heart affection, and no cough or pain in the chest. There was commencing optic neuritis. After consultation with Mr. Kinsey I operated. First a small trephine was applied just above and behind the meatus, and the middle fossa of the base of the skull was opened. The dura mater was found to be healthy. Next, the mastoid antrum was opened. The bone behind this was very soft, and whilst gouging it a most offensive smell arose. An abscess was opened lying between the bone and the lateral sinus, and about two drachms of foul-smelling pus were evacuated. The wall of the lateral sinus was thickened, discoloured, and sloughing. A free escape was provided for the matter. In the absence of rigors it was not considered necessary to tie the internal jugular vein. Next morning the temperature was $100 \cdot 4^{\circ}$ and the pulse 80 . About noon he had a rigor and the temperature rose to $104^{\circ}$. At 3 P.M. I tied and divided the internal jugular vein at about the level of the cricoid cartilage. At that point the common facial vein joined it. There was a free current in the facial vein, but none in the jugular, above their junction. 'The ligatures were applied above their junction. The ear wound was then reopened and the wall of the lateral sinus cut away, exposing a firm, dark blood-clot filling the sinus. 'The same evening I was laid up with influenza, so that for the greater part of the further treatment and notes I am indebted to Mr. Kinsey. After this, symptoms supervened which gave rise to considerable anxiety as to whether or not a cerebral abscess was forming. The boy becane very emaciated. On the 11th the stitches were removed from the wound in the neck, which had healed oy first intention. On that day he began to complain of frontal headache, was very restless, and vomited. He also became drowsy, in consequence of which, on the 15th. tlie mastoid wound was reopened and enlarged. All granulations were scraped away and about two drachms of pus let out from the occipital portion of the lateral sinus. A probe was passed as far as the torcular Herophili and caused slight bleeding. A drainage-tube was inserted in the sinus and the mirldle ear thoroughly scraped out. On the 17 th he had a rigor, which was followed by a swelling on the left side of the neck, which spread upwards over the face and downwards below the clavicle. On the 19th an incision was made in the swelling in the neck, and some foul-smelling pus eracuated After this:-all went well, and by May 16th all the wonnds were healed.

Remarks.-This case exemplifies an interesting sequence of events-viz., chronic otorrhœea, suppuration in the mastoid antrum, subdural abscess, and thrombosis of the lateral sinus. The course of events, modified by treatment, was as follows : (1) The subdural abscess and mastoid antrum were cleared out and drained, but already the septic inflammation. had involved the lateral sinus; (2) absorption of septic material from the thrombus necessitated ligature and division of the internal jugular vein to cut off the source of infection from the general circulation-the lateral sinus was opened to permit of the escape of the breaking-down clot; (3) it. was necessary to reopen and enlarge the mastoid wound to allow pus to escape from the lateral sinus; and (4) the subcutaneous abscess in the neck was opened. The cause of this abscess seems to have been one of two. Either it was cellulitis due to septic material carried by the lymphatics from the wound behind the ear, or it was due to the breaking down of the clot in the jugular vein, between the base of the skull and the ligature.

Obliteration of the left internal jugular vein, by clot or ligature gives rise to less disturbance of the cerebral circulation than obliteration of the right vem, ass the superior longitudinal sinus usually enters the right lateral sinus, which is then much the largest. The abnormally low entrance of the common facial vein into the jugular was also of interest, as through it the blood coming from the brain through the angular vein was able to reach the jugular below the ligature. The question arises, Should I have ligatured the lateral sinus outside the: torcular Herophili, as is advised by Mr. Arbuthnot Lane? I think it would have been wise to have done so, and certainly better surgery. Suppuration must have occurred as far as the torcular Herophili, and one sees no reason why it showld not have gone on extending further. In fact, it probably would have done so had not a drainage-tube been introduced into the sinus. The risk incurred by ligaturing the sinus must be small compared with that from the extension of the septic thrombus.

Bedford.

\section{A CASE OF}

\section{TUBERCLE JOF THE LEFT OPTIG}

\section{THALAMUS EXHIBITING INTENTION-}

\section{TREMOR, AND ATTACKS OF TETANOID RIGIDITY; NECROPSY; REMARKS.}

BY ${ }^{-}$ARNOLD J. EDWARDS, M.D. VICT.,

RESIDENT MEDICAL OFFICER TO THE CHORLTON-UPON-MEDLOCK DISPENSARY, MANCHESTER.

A Bor aged six years was admitted as a home patient at the Chorlton-upon-Medlock Dispensary under my care on Dec. 17 th, 1894 . The patient was apparently quite well untileseven weeks before admission, when the mother notices that he dragged his right leg on walking. Two or three thys after this it was observed, when he was taking his food, that he held the "spoon in his left hand, and upon his mother insisting that he made use of the right hand for that purpose this? Iatter hand began to tremble. At first the trembling was slight, but it gradually got more and more marked. For the last three weeks he had complained of severe frontal headache, and there had been vomiting for the last four. days. Lately, also, he had not seemed to see things well. The father died two years ago of apoplexy. 'The mother" gave a history of four miscarriages out of eight pregnancies: and had had a sore-throat for six months at a time. The mother's father died of phthisis. On admission an exceedingly well-marked, coarse, jerky tremor was seen in the right arm on movement. This disappeared entirely wher the arm was at rest. The movements came largely from the: shoulder. 'There was no nystagmus or syllabic speech. The right arm and leg were distinctly weaker than those of the left. There was no facial paralysis. There was well-marked and persistent ankle-clonus on the right side, but ankleclonus was not obtained on the left. Both wrist-jerks were present and about equal upon the two sides. The epigastric. abdominal, cremasteric, and plantar reflexes were al obtained, but showed no: difference on either side. Therc 
was marked rigidity noticed on passive movement of the right knee-joint. The patient had difficulty in standing unsupported, but closing the eyes did not, increase it, nor was there any sign of reeling in one or other direction. With assistance he was able to walk, and the gait was distinctly ataxic. Sensation was universally normal. The bladder and rectal functions were normal. There were no signs of congenital syphilis, and the lungs appeared quite healthy. On December 19th the romiting had quite ceased under bismuth, but treatment had in no way influenced the headache. On the 22nd there was well-marked optic neuritis of the left eye. There appeared also to be inflammation of the right nerve, but of this I could not be quite certain, as conjunctiritis with a slightly cloudy cornea was present on that side, and the concomitant blepharospasm also rendered ophthalmoscopic examination exceedingly difficult. The other cranial nerres appeared to be normal. Towards the close of the somewhat prolonged ophthalmoscopic examination the patient was suddenly seized with an attack of tetanoid rigidity. $\mathrm{He}$ became unconscions, the head was bent back, the spine arched, and the whole body became extremely rigid; the teeth were clenched and both eyes were turned to the right. The face preserved its natural colour. This condition was kept up for about three minutes, and then the muscles gradually relaxed and there was a return to complete consciousness. This tonic condition was not succeeded by any clonic contractions. The mother now told me that he had three similar attacks during the preceding night. I put the patient on large doses of iodide of potassium, combined with mercurial inunctions. On the 23rd he had three attacks of tetanoid rigidity between the hours of six and eight in the morning, the last one being the severest experienced. He fell asleep, worn out, after each attack. When awake he was constantly moaning and complaining of his head. On the 24th he had five attacks of tetanoid rigidity early in the morning. They followed rapidly upon one another. The intention-tremor was not quite so marked as when first seen, and the grasp of the right hand was weaker. On the 25th he had no control either over the bladder or the rectum. He died at 11 P.M.

Necropsy.- This was held on Dec. 26th, sixteen hours

FIG. 1.

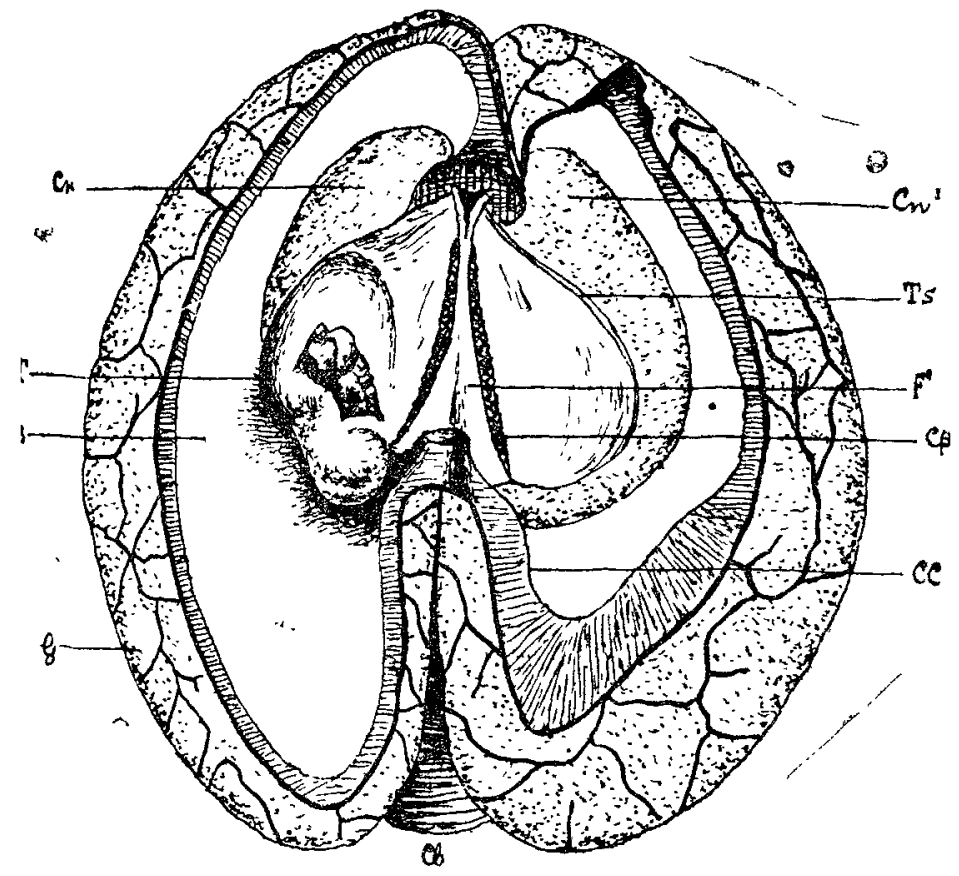

Both lateral ventricles were partially opened out, and displayed $T$, a tuberculous growth in the left optic thalamus; $B$, body of T, a tuber verticter left lateral ventriele; On, left caudate nucleus; $\mathrm{Cn}^{1}$, right caudate nucleus; $\mathrm{F}$, fornix , $\mathrm{Cp}$, choroid plexuses; Ts, tænia semicircularis; $C C$, corpus callosum; $G$, cortical grey matter;
and $C b$, cerebellum. (Diagram one-third natural size.)

after death. Post-mortem rigidity was very marked. There was extensive dorsal hypostasis. I could obtain permission to examine the brain only. The skull-cap was normal. The membranes were congested, but did not show any signs of inflammation. A distinct firm tumour could be felt in the left side of the brain. On opening the left lateral ventricle in the usual way a very considerable quantity of clear serous fluid gushed out. There was no excess of fluid in the right lateral ventricle. The tumour was about the size of a large walnut, and was found to be situated in the left ontic thalamus. (See Fig. 1.) A vertico-transverse section through the tumour and left cerebral hemisphere showed that the growth was pressing on the left internal capsule. (Soe Fig. 2.) The floor of the fourth ventricle presented no signe of pressure, and sections through the medulla and the upper cervical region of the cord appeared normal. Microscopical

FIG. 2.

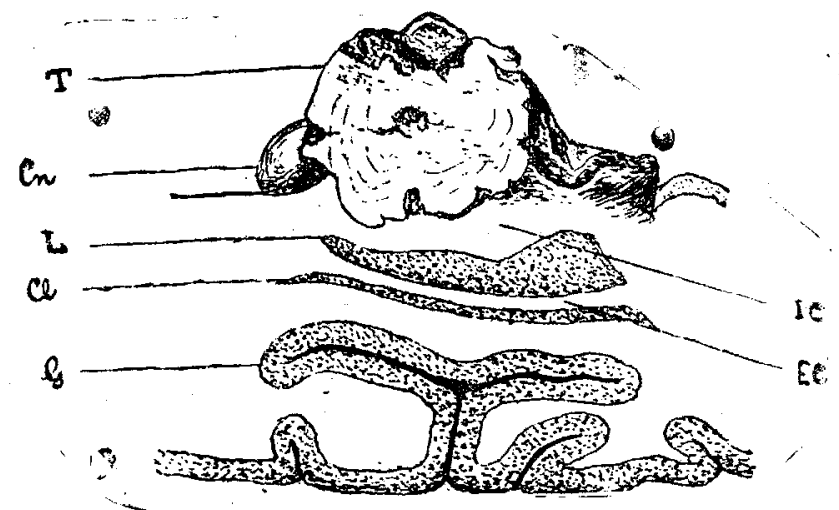

Vertico-transverse section through the growth and leff cerebral hemisphere. T, tumour; IC, internal capsule; EC, external capsule; L, lenticular nucleus ; $\mathrm{Cl}$, claustrum Cn, caudate nucleus; G, cortical grey matter. (Natural size.)

examination of the growth showed it to be undoubtedir tuberculous.

Remarks. - The occurrence of attacks of tetanoid rigidity and the presence of well-marked intention-tremor in the right arm are the principal features of interest in the above case. General tetanic rigidity, constant or paroxysmal, has been met with in several examples of tumour of the pons and of the cerebellum, but, after a careful review of the literature of the subject, I have been unable to find a single instance of tumour of the optic thalamus in which attacks of tetanoid rigidity were noted. The rigidity in this case is exceedingly difficult of explanation; in tumours of the pons or cerebellum it is possibly due to pressure upon the medulla. The localised intention-tremor is of interest as bearing upon the pathology of the intention-tremce seen in disseminated sclerosis. Cases such as the above, where we have a definite and localised lesion in the brain, together with trembling on movement confined to a limb, are especially valuable in helping us to arrive at a true conception of the causation of intention-tremor. The tumour here was pressing on the motor paths in the internal capsule, and it seems to me very probable that the tumour would act in a precisely similar manner to a sclerotic patch in the internal capsule. The nerve fibres would be unequally implicated the functions of a few would be destroyed, the conducting power of a considerable number would be impaired, while others might escape entirely. The stimuli proceeding from the cortex to certain muscles would, owing to the diminished conducting power of the supplying nerve-fibres, be too few, and as a consequence tremor would result; again, unless the amount of contraction of each of the antagonistic or regulating muscles-which are brought into play in all coördinated move ments-is exactly graduated, the balance would be disturbed and incoördination as well as tremor would follow. The implication of the nerve fibres to certain muscles, with escape of the nerve fibres to antagonistic muscles, would bring about this incoördination. Further, it is noteworthy that the tremor in the above case was very slight at the commence ment, then gradually got more and more pronounced, untit finally, in the later stages of the disease, it again became less marked. It will be observed, also, that as the tremor diminished the paralysis increased. These facts would appear to indicate that the tumour was rapidly increasing in size and destroying in its progress more and more nerve tubules.:

Manchester.

Superannuation Allowance.-Mr. Edward L. Webb, M.R.C.P. Edin., M.R.C.S. Eng., late Medical Officer of the second district, St. George's, Hanover-square, has been granted a superannuation allowance of $£ 76$ per annum. 
A CASE SHOWING THE VALUE OF THE LEFT SUPRA-CLAVICULAR ADENOPATHY AS A REVEALING SYMPTOM OF INTRA-ABDOMINAL CANCER; WITH REMARKS.

\section{BY W. ROGER WILLIAMS, F.R.C.S.}

Several cases have now been recorded by Continental observers demonstrating the frequency of the association of enlargement of the left supra-clavicular lymph glands with intra-abdominal malignant disease, to which Troisier ${ }^{2}$ first directed attention in 1888. As the subject has escaped notice in this country, notwithstanding its great importance in diagnosis, I think the following case will be of interest.

A married woman aged fifty-six, the mother of six children, having for some months suffered from gradually progressive anæmia and loss of strength, together with failure of appetite, constipation, nausea, and dyspeptic symptoms, in August, 1894, began also to experience pain in the epigastric region, for which she consulted a medical man in September. I first saw her in the following October, when she was markedly anæmic and sallow. The ingestion of solid food caused epigastric pain and after a time nausea and vomiting. She complained of a swelling in the epigastric region, but upon examination no intra-abdominal tumour could be detected. The stomach was not dilated, and there were no signs of obstruction. The liver and spleen seemed normal. There was no history of hæmatemesis or coffee-ground vomit. At this time she was very subject to alternate flushing and pallor of the cheeks and extremities, the fingers often becoming quite dead, as in Raynaud's disease. She was also subject to palpitation of the heart and to occasional syncopal attacks. The urine contained neither sugar nor albumen. Under the influence of rest in the recumbent position, with none but peptonised fluid foods, together with medicines containing belladonna and carbolic acid, the pain subsided, and there was temporary improvement. It soon became obvious, however, that the weakness was increasing; and subsequentiy nausea, vomiting, and thirst became prominent symptoms. In January, 1895, I saw her again, when she was weaker, paler, and more sallow than on the previous occasion. I was unable to detect any intra-abdominal tumour. The case presented many of the features of pernicious anæmia. She was treated with "bone marrow" and Fowler's solution. This treatment soon had to be given up on account of the pain and vomiting it excited. In April an intra-abdominal tumour was discovered. I saw her again in May, when the emaciation, pallor, and weakness were very great. The vaso-motor symptoms had quite disappeared. Nausea, vomiting, and epigastric pain after food still continued, but there was no thæmatemesis. On abdominal palpation a circumscribed mobile intra-abdominal tumour, about the size of a small turnip, could be felt rather to the right of the median line, midway between the umbilicus and xiphoid. It was dull over its anterior surface. There appeared to be no dilatation of the stomach; the dimensions of the liver and spleen were normal; there was no umbilical retraction. The left supra-clavicular lymph glands, as well as those at the upper part of the axilla, were enlarged and hard; these by interfering with the venous circulation had caused the cedema of the head and forearm. This condition was of rather less than a week's duration. It was evidently due to dissemination of the disease in the glands through the medium of the thoracic duct. The recognition of this symptom completely negatived any exploratory operation. Death ensued about five weeks later, and there was no necropsy. The patient was partially unconscious, with muttering delirium, for some days before the end. The rapid formation of the tumour, its mobility, the considerable size attained, the absence of hæmatemesis, gastric obstruction, hepatic and splenic enlargement, and finally the dissemination by the lymphatics, all seem to indicate a tumour of omental origin-probably a malignant endothelioma.

Remarks. - I will conclude with a brief résumé of what is known of the left supra-clavicular adenopathy. The

1 Bulletins et Mémoires de la Société Médicale des Hôpitaux, Jan. 13th, 1888; also Archives Générales de Médecine, February and March, 1889 . first indication of the affection generally is the enlargement and induration of a single lymph gland, situated behind the posterior border of the lower part of the left sterno-cleido-mastoid muscle. Subsequently adjacent glands become similarly affected; and in the event of life being prolonged they ultimately manifest all the symptoms of malignant disease. This occurs without any of the intervening structures, prevertebral glands, lungs, \&c., bein invaded. All the different varieties of intra-abdominal malignant disease may cause this affection; but it has hitherto been observed with especial frequency in association with cancer of the uterus. It seems probable that this curious pathological condition is due to reflux of lymph, charged with cancer cells, from the thoracic duct into which the cancer cells find their way from infected lumbar glands. I need hardly insist on the great importance of thi manifestation in the diagnosis of obscure intra-abdominal disease and as a contra-indication to operation. The glandular enlargement generally first makes its appear. ance at a late stage of the abdominal disease; it has however, been known to have appeared nearly two years before death. Several instances of its occurrence have lately been reported secondary to malignant disease of the testicle? Vidal has met with a case secondary to cancer of the stomach. $^{3}$ Spinelli has tabulated thirty-four examples of this condition, ${ }^{4}$ and he points out that the glandular enlargement may be accompanied by painful sensations in the region of the neck, shoulder, and arm. Care must be taken not to confuse this adenopathy with the "pseudo-lipome susclaviculaire" of Verneuil, of which I have given an account elsewhere, ${ }^{5}$ the latter affection is simply an overgrowth of the fibro-fatty tissue of the supra-clavicular fossa, both sides being affected; and it is usually met with in well. nourished middle-aged women otherwise in good health. Preston.

\section{NOTE ON A RARE FORM OF POST-} PARTUM HAMORRHAGE.

By Surgeon-Captain A. W. D. LeaHy, M.D. Durh., F.R.C.S. ENG., INDIAN MEDICAI SERVICE.

IN the form of a reprint from the Comptes-Rendus du Congrès Périodique International de Gynécologie et d'Obstétrique Dr. R. A. Gibbons has published a very interesting brochure on what he terms "Tonic Spasm of the body of the Uterus as a cause of Post-partum Hæmorrhage." The condition to which Dr. Gibbons calls attention as a cause of post-partum hæmorrhage is a very rare one, and it is possible that its very occasional occurrence may have led many practical obstetricians to even doubt its existence. That such a condition does occasionally occur causing post-partum hæmorrhage I for one do not doubt, and I can recall two distinct cases of its occurrence in my own practice. The majority of us have been taught, and believe, in the correctness of what the late Professor Matthews Duncan lays down in his writings. Dr. Duncan says: "The proposition I enunciate is that it has rerir been shown that uterine hæmorrhage of the ordinary postpartum kind ever takes place from the uterus when it is in a state of moderately firm contraction." But the condition of the uterus to which Dr. Gibbons directs attention as a cause of post-partum hæmorrhage is one which its external appearances would lead one to believe was a state of moderately firm contraction, but which internal examination shows to be one of tonic spasm of its walls. The two cases to which I have referred as having occurred in my practice presented themselves at an interval of fourteen years. The first I met with during my period of residence as obstetrical officer to the Charing-cross Hospital, London. The second occurred to me here in Calcutta three years ago. They were curiously alike, and as they may prove of some interest to my professional brethren $I$ append short notes of each.

CASE 1.-A woman aged twenty-seven, married seren

2 Troisier: Archives Générales de Médecine, August, 1893. Poncek: Mercredi Médical, Jan. 3rd, 1894.

3 Bulletirs et Mémoires de la Société Médicale des Hôpitaur, December, 1893.

4 Rivista di Clinica e Terapia, No. 8, 1893, p. 397

5 Transactions of the Pathological Society of London, 1890, p. 302. 